\title{
Eiken syndrome
}

INSERM

\section{Source}

INSERM. (1999). Orphanet: an online rare disease and orphan drug data base. Eiken syndrome. ORPHA:79106

A rare, genetic, primary bone dysplasia syndrome characterized by multiple epiphyseal dysplasia, severely delayed ossification (mainly of the epiphyses, pubic symphysis, hands and feet), abnormal modeling of the bones in hands and feet, abnormal pelvis cartilage persistence, and mild growth retardation. Calcium, phosphate and vitamin D serum levels are typically within normal range, while parathyroid hormone serum levels are normal to slighly elevated. Oligodontia has been rarely associated. 